\title{
Improved wire-guided basket for intrahepatic stone extraction in a patient after pancreatoduodenectomy
}

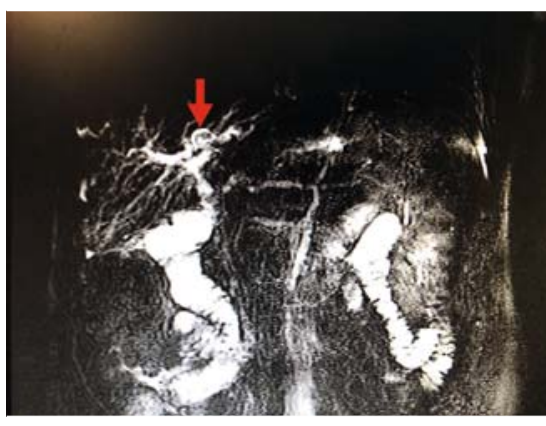

- Fig. 1 Magnetic resonance cholangiopancreatography suggested stones in the common and left hepatic duct (red arrow) with proximal intrahepatic bile duct dilatation.

A 61-year-old man with symptoms of chills and high fever had undergone pancreatoduodenectomy in 2009 because of pancreatic serous cystadenoma. Magnetic resonance cholangiopancreatography suggested stones in the common and left hepatic duct ( $>$ Fig. 1). The type of the gastrointestinal reconstruction was ascertained from surgical records, and we used a cap-assisted colonoscope (PCF-PQ260; Olympus Medical Systems, Tokyo, Japan) for endoscopic retrograde cholangiopancreatography (ERCP). The removal of the common hepatic duct stones followed the ERCP sequence: intubation to the afferent limb, biliary cannulation, balloon dilation of the distal bile duct, and balloon-assisted stone extraction. When the left intrahepatic duct stones could not be removed using to this method, we carried out wireguided cannulation using an improved single-lumen stone extraction basket, in which a hole was made with the tip of a needle ( $\mathbf{F i g . 2}$ ) to allow it to be advanced over the guidewire ( $\mathbf{F i g} \mathbf{3}$ ) into the desired segmental duct ( $\mathbf{F i g} \mathbf{4}$ ). The stones were engaged and dragged into the intestinal tract without removing the guidewire ( $\triangleright$ Video 1 ). This pro-

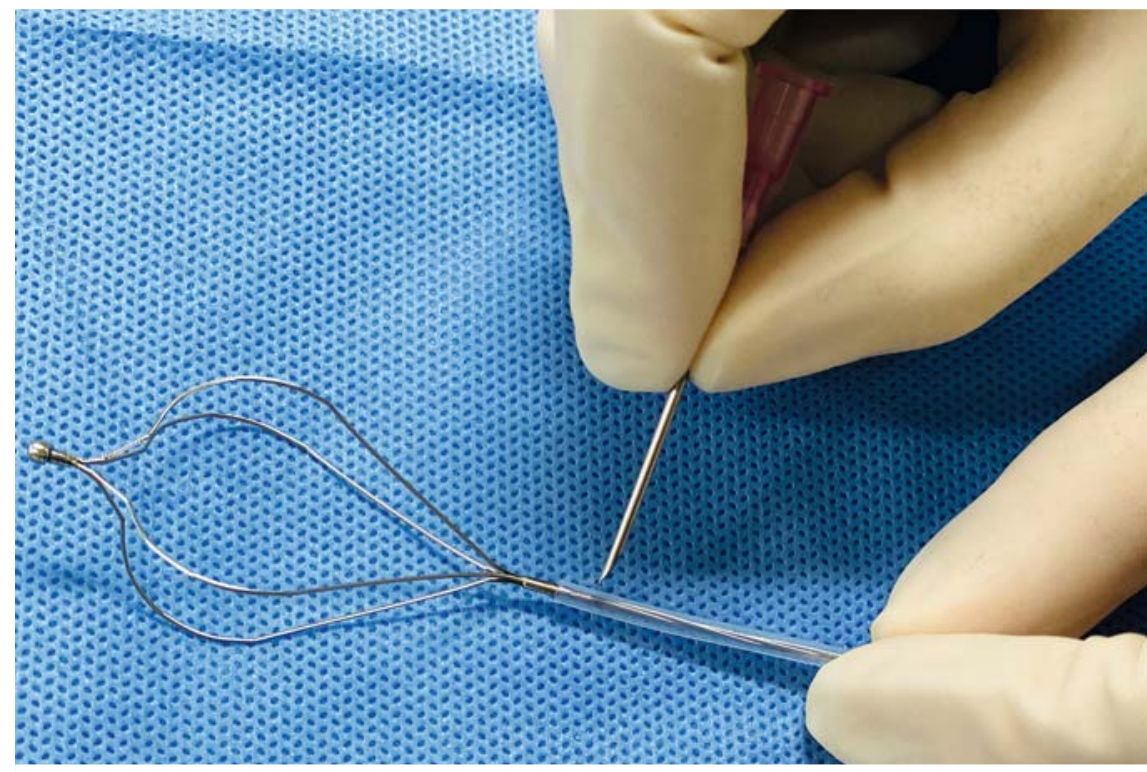

- Fig. 2 The 7-Fr catheter of the basket (Vedkang; Jiangsu, China) was dug out with 1.2-mm needle from a $20-\mathrm{ml}$ sterile syringe.

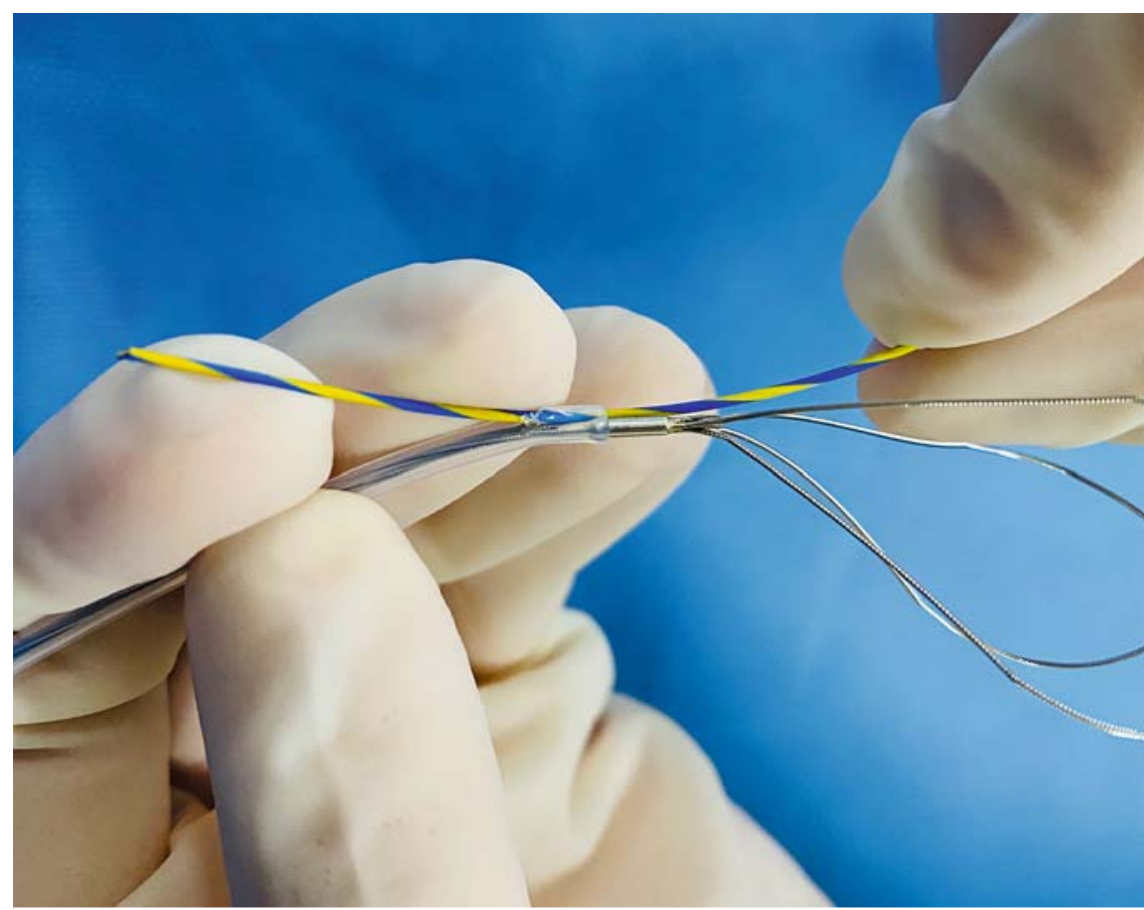

- Fig. 3 The catheter was passed over a 0.035 -inch guidewire (Vedkang) and advanced into the endoscope. 


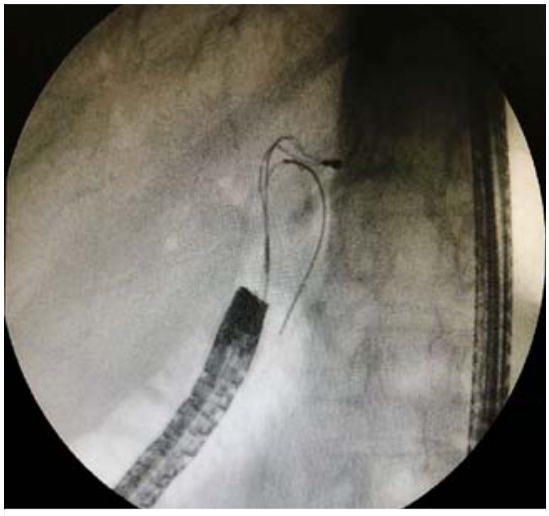

- Fig. 4 The wire-guided basket placed into the segment and opened with the guidewire in the desired intrahepatic duct.

cess was repeated until complete removal of the stones was accomplished. The patient was discharged on the 2nd day after the operation. During the following 3 weeks, there were no abnormal symptoms.

Endoscopic extraction of intrahepatic duct stones with conventional stone retrieval baskets is sometimes difficult [1], especially in patients with surgically altered anatomy [2]. Understanding the reconstruction that has been carried out helps endoscopists to select the appropriate endoscope and achieve biliary access $[3,4]$. Intrahepatic duct stone removal can be difficult because of altered anatomy as well as the limitations of stone extraction devices [2]. We offer here an improvement of the single-lumen-type basket that can be used in combination with a guidewire; it is not as rigid as the double-lumen or any other attached types [5]. Its use in our center proves that it is safe, and we think it is an easy and cheap alternative for use in developing countries in patients with intrahepatic duct stones. Prospective randomized controlled trials are warranted in terms of safety, efficacy, and cost effectiveness.

Endoscopy_UCTN_Code_TTT_1AR_2AK

\section{Competing interests}

The authors declare that they have no conflict of interest.

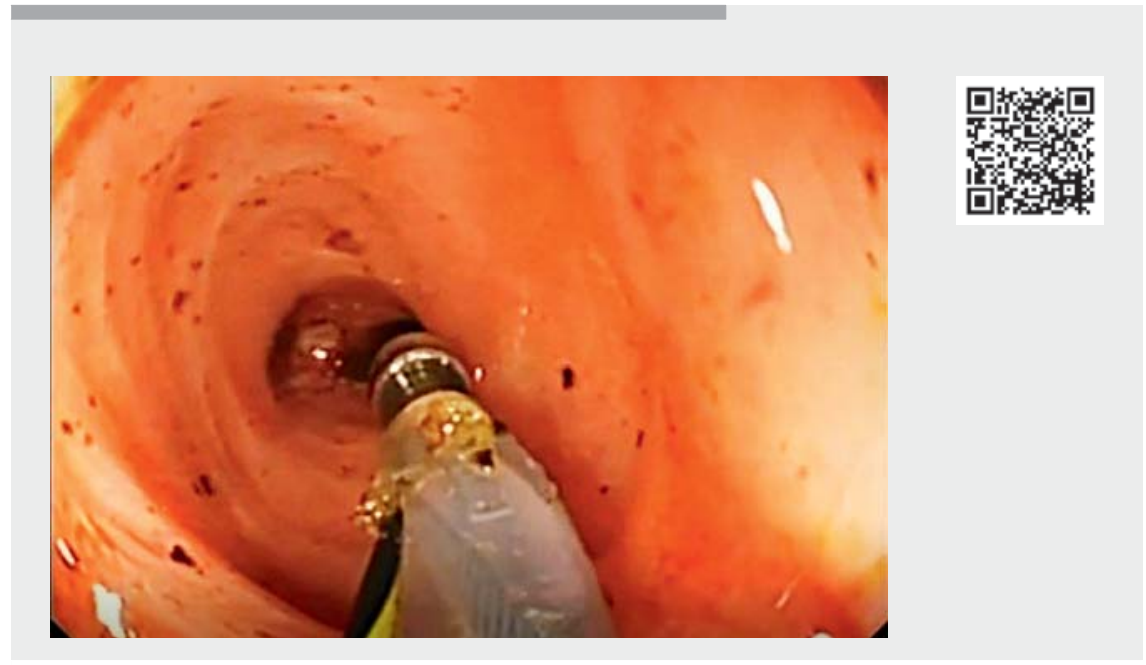

Video 1 Extraction of left main intrahepatic duct stones using an improved wire-guided basket.

The authors

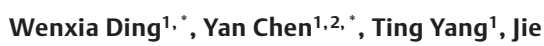
Chen ${ }^{1,2}$

1 Digestive Endoscopy Center, Changhai Hospital, Shanghai, China

2 Department of Gastroenterology, Changhai Hospital, Shanghai, China

\section{Corresponding author}

\section{Jie Chen, MD}

Department of Gastroenterology and Digestive Endoscopy Center, Changhai Hospital, 168 Changhai Road, Shanghai 200433, P. R. China

cjlj702@163.com

\section{References}

[1] Chan AC, Chung SC. New wire-guided basket for intrahepatic stone extraction. Gastrointest Endosc 1999; 50: 401-404

[2] Nakai Y, Kogure H, Yamada A et al. Endoscopic management of bile duct stones in patients with surgically altered anatomy. Dig Endosc 2018; 30 (Suppl 1): 67-74

[3] Gasmi M, Gonzalez JM, Barthet M. Endoscopic ultrasound-directed transgastrojejunal ERCP: a new technique to treat biliary stricture through the afferent limb after Whipple surgery. Endoscopy 2020; 52: E441-E442

* Wenxia Ding and Yan Chen contributed equally to this work.
[4] Nakaji S, Hirata N, Yamauchi K et al. Endoscopic retrograde cholangiopancreatography using a cap-assisted highly flexible colonoscope in patients with Roux-en-Y anastomosis. Endoscopy 2014; 46: 529-532

[5] Okabe Y, Ishida Y, Kuraoka K et al. Endoscopic bile duct and/or pancreatic duct cannulation technique for patients with surgically altered gastrointestinal anatomy. Dig Endosc 2014; 26 (Suppl 2): 122-126

\section{Bibliography}

Endoscopy 2022; 54: E59-E60

DOI 10.1055/a-1352-2085

ISSN 0013-726X

published online 5.3.2021

(c) 2021. Thieme. All rights reserved.

Georg Thieme Verlag KG, Rüdigerstraße 14, 70469 Stuttgart, Germany

\section{ENDOSCOPY E-VIDEOS}

https://eref.thieme.de/e-videos

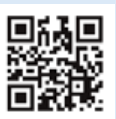

Endoscopy E-Videos is an open access online section, reporting on interesting cases and new techniques in gastroenterological endoscopy. All papers include a high quality video and all contributions are freely accessible online. Processing charges apply (currently EUR 375), discounts and wavers acc. to HINARI are available.

This section has its own submission website at https://mc.manuscriptcentral.com/e-videos 